agents. Biochem. Biophys. Acta, 718: 26 (1982).

13. Koo, S. I. and Williams, D. A.: Relationship between the nutritional status of zinc and cholesterol concentration of serum lipoproteins in adult male rats. Am. J: Clin. Nutr., 34: 2376 (1981).

14. Lei, K. Y., Abbasi, A., and Prasad, A. S.: Function of pituitary-gonadal axis in zinc-deficient rats. Am. J. Physiol, 230: 1730 (1976).

15. Loor, F.: Plasma membrane and cell cortex interactions in lymphocyte functions. Adv. Immunol., 30: 1 (1980).

16. Malmquist, J., Israelsson, B., and Ljungqvist, U.: Inhibition of human liver membrane adenylate cyclase by zinc ions. Horm. Metab. Res., 11: 530 (1979).

17. Miyachi, Y., Vaitukaitis, J. L., Nieschlag, E., and Lipsett, M. B.: Enzymatic radioiodination of gonadotropins. J. Clin. Endocr., 34: 23 (1972).

18. Miyachi, Y., Mizuchi, A., and Sato, K.: Preparation of iodinated cyclic GMP derivates by a lactoperoxidase method. Anal. Biochem., 77: 429 (1977).

19. Miyachi, Y. and Kawamura, H.: Gonadotropin. Jap. J. Clin. Med., 39: 2954 (1981).

20. Nieschlag, E. and Loriaus, D. L.: Radioimmunoassay for plasma testosterone. Z. klin. chem. klin. Biochem., 10: 164 (1972).

21. Prasad, A. S. and Oberleas, D.: Thymidine kinase activity and incorporation of thymidine into DNA in zinc deficient tissue. J. Lab. Clin. Med., 83: 634 (1974).

22. Rajaniemi, H., Manninen, M., Metsikkö, K., and Huhtaniemi, L.: Dissociation of human choriogonadotropin from the pseudopregnant rat ovary as a complex to a receptor fragment during perifusion and incubation. Biochem. Biophys. Acta, 714: 271 (1982).

23. Sato, K., Miyachi, Y., Ohsawa, N., and Kosaka, K.: In vitro stimulation of steroidogenesis in rat testis by cholera enterotoxin. Biochem. Biophys. Res.
Commun., 62: 696 (1975).

24. Sato, K., Miyachi, Y., Mizuchi, A., Ohsawa, N., and Kosaka, K.: Enzymatic radioiodination of succinyl cyclicAMP tyrosine methylester by lactoperoxidase and radioimmunoassay for cyclicAMP. Endocrinol. Jap., 23: 251 (1976).

25. Scrutton, M. C. Wu, C. W and Goldthwait, D. A.: The presence and possible role of zinc in RNA polymerase obtained from Escherichia coli. Proc. Natl. Acad. Sci. USA, 68: 2497 (1971).

26. Slater, J. P., Mildvan, A. S., and Loeb, L. W.: Zinc in DNA polymerases. Biochem. Biophys. Res. Commun., 44: 37 (1971).

27. Steiner, A. L. Parker, C. W., and Kipnis, D. M.: Radioimmunoassay for cyclic nucleotides. I. Preparation of antibodies and iodinated cyclic nucleotides. J. Biol. Chem., 247: 1106 (1972).

28. Underwood, E. J. Zinc. In: Trace elements in human and animal nutrition 4th Ed: pp. 196-242 (Academic Press, New York, 1977).

29. Weatherbee, J. A.: Membranes and cell movement: Interaction of membranes with the proteins of the cytoskeleton. In: A. L. Muggleton-Harris: International Review of Cytology. Suppl. 12. pp. 113-176 (Academic Press, New York, 1981).

30. Requests for reprints should be addressed to: Dr. Yoshikazu Nishi, Department of Pediatrics, Hiroshima University School of Medicine, 1-2-3 Kasumi, Minami-ku, Hiroshima 734, Japan.

31. This research was supported in part by a Grant-in-Aid for Scientific Research (Project No. 57770633) from the Ministry of Education, Science and Culture of Japan and a Grant-in-Aid from Morinaga Hoshikai.

32. We are grateful to Dr. Alice S. Cary for assistance in preparing this manuscript.

33. Received for publication November 16, 1982.

34. Accepted for publication June 6, 1983.

\title{
Kinetics of Intestinal Calcium Transport during Maturation in Rats
}

\author{
FAYEZ K. GHISHAN, ${ }^{(18)}$ PAUL PARKER, SHARON NICHOLS, AND ANASTACIO HOYUMPA \\ Vanderbilt University Medical Center and VA Medical Center, Departments of Pediatrics and Medicine, \\ Nashville, Tennessee, USA
}

\section{Summary}

Young animals absorb and retain more calcium (Ca) than their older counterparts. The mechanism(s) for this age-related difference and the kinetics of intestinal calcium transport during maturation are not known. We determined, therefore, the unidirectional uptake and the transmural flux of $\left[{ }^{45} \mathrm{Ca}\right]$ in everted duodenal and jejunal sacs of suckling, weanling, adolescent, and adult rats using $\left[{ }^{3} \mathrm{H}\right]$ dextran as a marker of adherent mucosal volume. These measurements were carried out over a wide range of Ca concentrations $(0.5-30 \mathrm{mM})$. Results indicate an evolving pattern of intestinal calcium transport with different kinetic characteristics emerging as the animals matured. The active component of transport became more pronounced with increasing age. In adult rats $\mathrm{Km}$ and $\mathrm{Jmax}$ of $\left[{ }^{45} \mathrm{Ca}\right]$ duodenal and jejunal uptake were several-fold greater than corresponding values for suckling rats. Transport at higher calcium concentrations $(10-$ $30 \mathrm{mM}$ ) was non-saturable, and the 'permeability coefficient decreased with age. The transition to a more saturable process occurred around the time of weaning. These findings suggest that intestinal calcium transport is characterized by a maturation pattern that starts with a predominantly passive system during infancy and changes to a saturable active mechanism during maturation.
Studies of calcium balance indicate that calcium is absorbed and retained to a much greater degree in young growing animals than in their older counterparts. This suggests that calcium absorption and retention are governed by the particular need of the organism at the time, and requires a better understanding of calcium absorption.

The absorption of calcium from the intestine has been shown to possess characteristics of both active $(9,11,12)$ and passive (7) processes. In adult rats, and other animals, the rate of calcium transport is greatest in the proximal small intestine and decreases along the distal length of the gut. The uptake of calcium into the intestinal tissue is saturable and is adversely affected by anoxia, low temperature, and various metabolic inhibitors (13). These observations suggest an energy-requiring active process. Furthermore, the active transport of calcium appears to be dependent on $1,25-(\mathrm{OH})_{2}$ vitamin $\mathrm{D}_{3}(10)$. Features of active transport are generally seen at calcium concentrations below $10 \mathrm{mM}$. At higher concentrations, calcium transport is predominantly a passive process (17). These studies, however, were carried out using adult animals, and the possibility that calcium transport in the very young may be unique has received little attention. The present studies were undertaken to characterize calcium transport in segments of the duodenum and jejunum of rats during maturation. 


\section{MATERIALS AND METHODS}

Two days after birth, rat pups were distributed for suckling among the mothers to maintain a litter size of eight to nine pups until the beginning of the study. Mothers and post-weanling rats were fed a regular laboratory diet (Rat chow, Teklad Diets, Madison, WI). This diet contains $1.2 \%$ calcium, $0.8 \%$ phosphorus, and $170 \mathrm{U} / 100 \mathrm{~g}$ of vitamin $\mathrm{D}_{2}$. Adolescent and adult rats were purchased directly from Harlan Laboratory (Indianapolis, IN).

Measurements of unidirectional uptake of $\left[{ }^{45} \mathrm{Ca}\right] \mathrm{chloride}$ were carried out according to the method of Sallee et al. (11). Everted duodenal and jejunal sacs, $1.5-2 \mathrm{~cm}$ long, were obtained from suckling (2-wk-old), weanling (3-wk-old), adolescent (6-wk-old), and adult rats. Unfasted rats were killed by a blow on the head. All experiments were carried out between 8:00-11:00 a.m. The abdominal cavity was opened and the duodenal and jejunal segments were removed by stripping them from the mesentery. The intestinal segments were washed with cold $0.9 \%$ saline solution and everted over polyethylene tubing. The everted gut sacs were suspended in $20 \mathrm{ml}$ of a buffer solution which was oxygenated continuously. The buffer solution contained $125 \mathrm{mM}$ sodium chloride, $25 \mathrm{mM}$ sodium bicarbonate, and $5 \mathrm{mM}$ potassium chloride. The everted gut sacs were filled with the buffer solution, tied, and suspended in long threads. The mucosal bathing solution contained the same buffer solution as well, using different concentrations of $\mathrm{CaCl}_{2}$ (range, 0.1-10 mM), $\left[{ }^{45} \mathrm{Ca}\right]$ as a tracer and $\left[{ }^{3} \mathrm{H}\right]$ dextran as the marker of the adherent mucosal volume. A separate set of gut sacs was studied with high concentrations of $\mathrm{CaCl}_{2}(10-30 \mathrm{mM})$, when transport is linear with concentration, in order to measure the permeability coefficient.

The suspended sacs remained in the incubation solution at $37^{\circ} \mathrm{C}$ for a period of $3 \mathrm{~min}$ in order for transport to proceed, then were quickly removed and rinsed in cold buffer solution. The contents of each sac were saved for the determination of transmural flux (see below). The emptied sacs were then placed on moistened filter paper. The ends of each sac were cut off and discarded; the central cylinder was placed in a pre-weighed scintillation vial, oven-dried at $93^{\circ} \mathrm{C}$ overnight, then cooled and the dry tissue weight determined. The dry tissue was saponified with $0.8 \mathrm{ml}$ of $7.5 \mathrm{~N} \mathrm{NaOH}$, after $15 \mathrm{ml}$ of scintillation fluid was added and the solution agitated with a vortex mixer. The scintillation fluid contained $7 \mathrm{~g}$ PPO, $0.1 \mathrm{ml}$ of Trition X-100, and 80 $\mathrm{ml}$ of 2.5 N HCL. Counting was carried out in a Packard Tri Carb liquid scintillation spectrometer 2003 with automatic external standardization. The setting and detailed derivation of formulas are set forth by Sallee et al. (11).

To measure the rate of calcium appearance in the serosal compartment (transmural flux), the serosal content of the sac was emptied into a scintillation vial and additionally flushed with $2 \mathrm{ml}$ buffer. This volume was shown previously to achieve maximum recovery of radioactive material. Recovery rate was approximately $85 \%$. The vial was then placed in the oven until the fluid evaporated completely. The vial was left to cool, at which time $0.8 \mathrm{ml}$ of $7.5 \mathrm{~N} \mathrm{NaOH}$ and $15 \mathrm{ml}$ of the scintillation fluid was added. Radioassay was accomplished as described earlier.

Calculation of the kinetic parameters. The active component of duodenal and jejunal calcium uptake was calculated by subtracting the passive component from the total uptake at each calcium concentration. The passive component at each calcium concentration was calculated by multiplying the slope of linear line of uptake at high calcium concentration $(10-30 \mathrm{mM})$ by calcium concentration $(0.5-10 \mathrm{mM}) . \mathrm{Km}$ and $\mathrm{Jmax}$ values of the active calcium uptake were calculated by the use of Lineweaver double reciprocal plots.

Statistical analysis. The data were subjected to analysis of variance and $P$ value of 0.05 was taken as the minimal limit of significance (8).

\section{RESULTS}

Validation studies. The initial validation studies indicated that tissue uptake of calcium (Fig. 1A) and its rate of serosal appearance (Fig. 1B) were linear with time up to $6 \mathrm{~min}$. Similarly, tissue weight was directly proportional to calcium uptake and to its serosal appearance (Fig. 2). Results shown on Figures 1 and 2
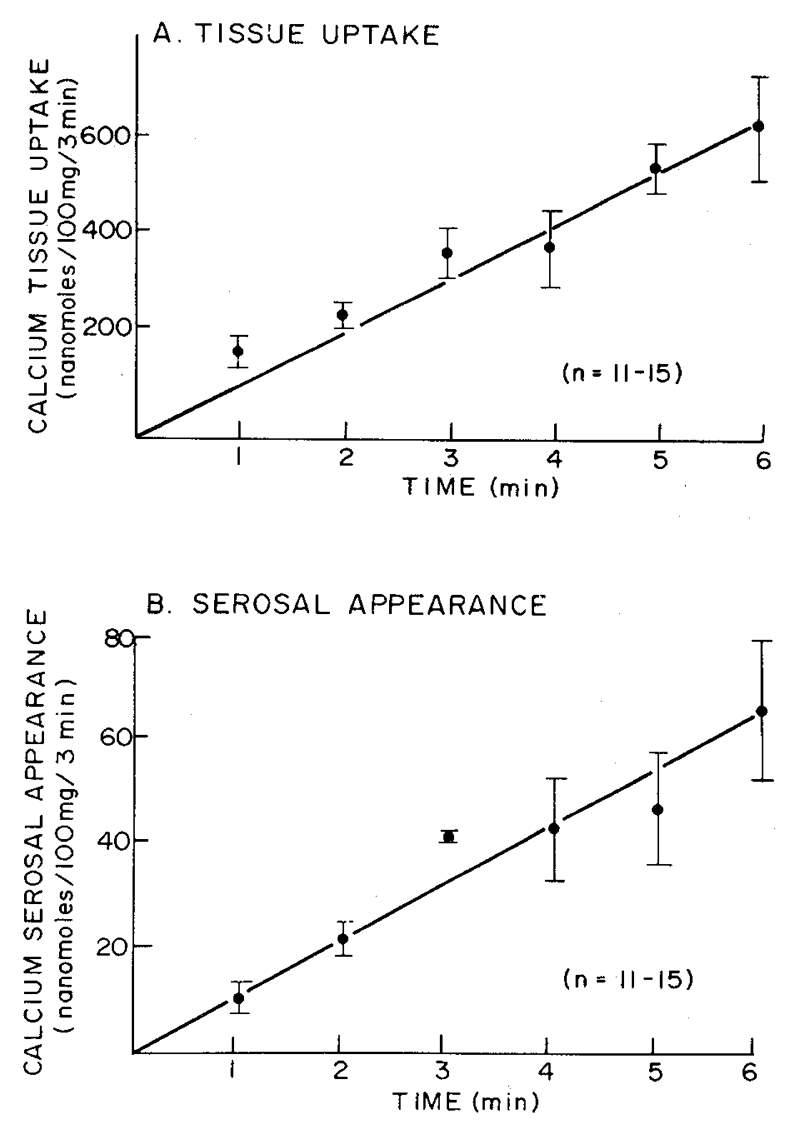

Fig. 1. (A) Serosal appearance of calcium in adolescent rats at calcium concentration of $5 \mathrm{mM}$. Each point represents mean $\pm \mathrm{SD}$. A linear relationship between time and serosal appearance of calcium is noted. $(B)$ Jejunal tissue uptake of calcium in the adolescent rats at calcium concentration of $5 \mathrm{mM}$. Each point represents mean \pm SD. A linear relationship between time and jejunal uptake of calcium is noted.

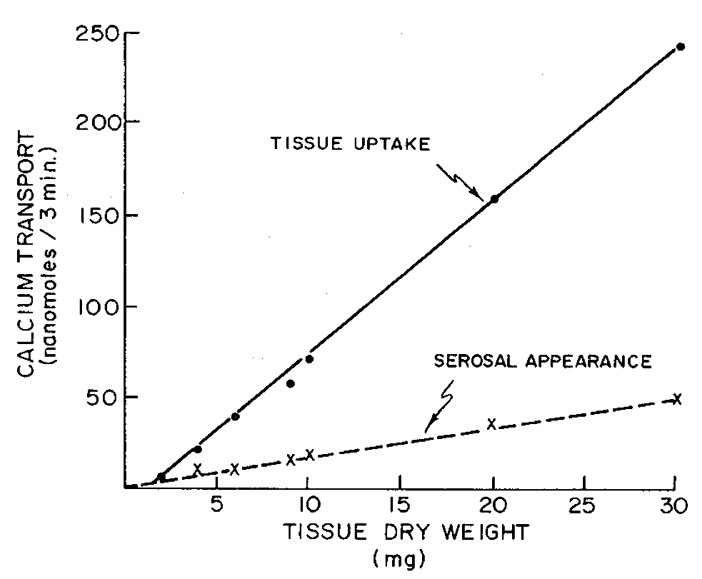

Fig. 2. Jejunal tissue uptake and serosal appearance of calcium in adolescent rats at calcium concentration of $5 \mathrm{mM}$ in relation to tissue dry weight. A linear relationship is noted between dry weight and both tissue uptake and serosal appearance of calcium. Tissue dry weights in the studies were between $8-12 \mathrm{mg}$. 
represent studies on jejunum of adolescent rats. Similar results were obtained with the duodenum and with the other groups of rats.

Tissue uptake at low Ca concentrations. Measurement of duodenal and jejunal tissue uptake of calcium over a range of 0.5 $10 \mathrm{mM}$ revealed an evolving pattern (Figs. 3 and 4 ) with different kinetic characteristics emerging as the animals matured. Saturation became more pronounced with increasing age, the difference between the suckling rats (2-wk-old) and adult rats was especially apparent.

Tissue uptake at high Ca concentrations. Unlike the saturable uptake of calcium at $0.5-10 \mathrm{mM}$, calcium uptake at $10-30 \mathrm{mM}$ concentration was non-saturable in both the duodenum and jejunum at all age groups. A plot of the slopes against age in the rats studied is shown in Figure 5. There was a decrease in the permeability coefficient with age. Comparison between the slopes (8) of the suckling and adult rats in both segments showed a highly significant difference $(P<0.01)$.

In the duodenal segment, $\mathrm{Km}$ and Jmax values were $0.58 \mathrm{mM}$ and $79 \mathrm{nmol} / 100 \mathrm{mg}$ dry weight $/ 3 \mathrm{~min}$, respectively. After weaning there was a 3-fold increase in $\mathrm{Km}$ values and 5-fold increase in Jmax values. There was a steady rise in Jmax values with age. $\mathrm{Km}$ values for adolescent and adult rats were similar. In the jejunal segments, $\mathrm{Km}$ and Jmax values for rats at each group showed a similar pattern with steady increase in Jmax values with age; however, $\mathrm{Km}$ values in the adolescent and adult rats were twice the corresponding values in the duodenal segments (Table 1).

Relationship between transmural transport and tissue uptake of calcium. Figure 6 depicts the relationship between serosal appearance of calcium and tissue uptake as tissue/fluid ratio in the duodenum at all age groups studied. As seen in the suckling rats, the ratio was below 1 at calcium concentration above $2 \mathrm{mM}$ indicating passive transport; however, in weanling, adolescent, and adult rats tissue/fluid ratio was greater than 1 at all calcium concentrations. A similar finding was also noted for the jejunal segment at all age groups studied.

\section{DISCUSSION}

The intestinal absorption of calcium during maturation has been the subject of at least two studies using rats. Batt and Schachter (1), using tissue slices, noted that a linear relationship in 3-d-old rats between the accumulation of calcium in duodenal tissue and calcium concentrations in the incubation medium $(0.1-2.0 \mathrm{mM})$, which suggested a passive process. This feature persisted until 2 wk of age, but at 3 wk a different relationship emerged, which suggested an active process. Our previous study, using an in vivo perfusion technique, also suggested passive calcium transport at $2 \mathrm{wk}$, but a saturable process at 3 and $6 \mathrm{wk}$. The first study measured net calcium accumulation at $1 \mathrm{~h}$ whereas the second study determined the rate of calcium disappearance and the lumen to mucosa flux of $\left[{ }^{45} \mathrm{Ca}\right]$ from the intestinal lumen under steady-state conditions (4). Neither study permitted the measurement of unidirectional tissue uptake of calcium and its transmural flux or the calculation of kinetic parameters.

The present study, designed to complement and extend the previous observations, allowed better characterization of the kinetics of calcium transport at various states of maturation in the rat. With maturation, there was gradual shift in the pattern of intestinal calcium transport (Figs. 3 and 4) from one of low
A. SUCKLING RATS

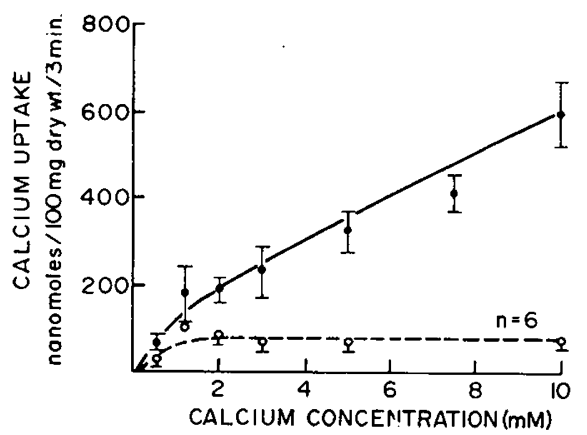

C. ADOLESCENT RATS

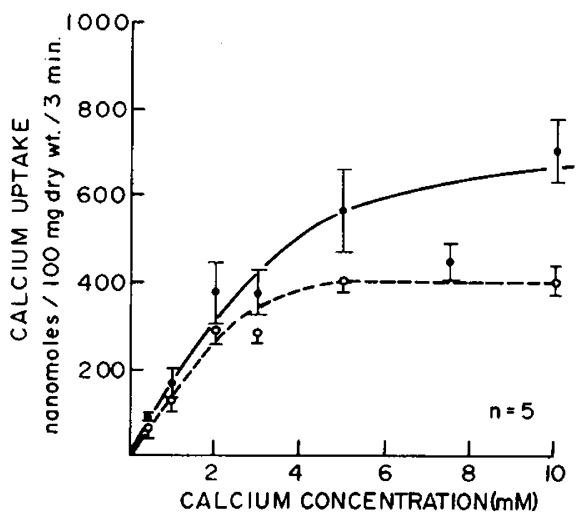

B. WEANLING RATS

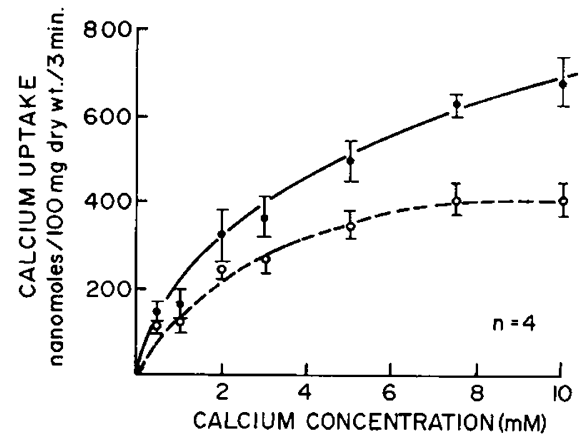

D. ADULT RATS

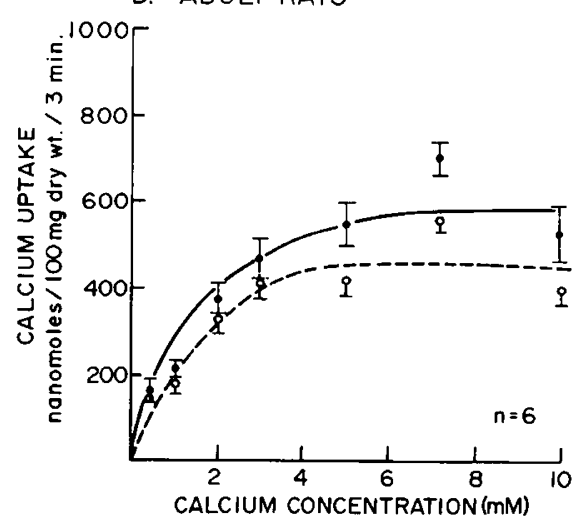

Fig. 3. Duodenal tissue uptake of calcium at $3 \mathrm{~min}$ in suckling, weanling, adolescent, and adult rats, in relation to calcium concentrations in the medium. With increasing age, a more saturable process is noted. Each point represents mean $\pm \mathrm{SD}$. The curves were analyzed using MichaelisMenten kinetics in the double reciprocal plot. The solid lines represent total uptake (active and passive) and the dashed lines represent the active component. $\mathrm{Km}$ and Jmax values at each group are shown in Table 1. 
A. SUCKLING RATS
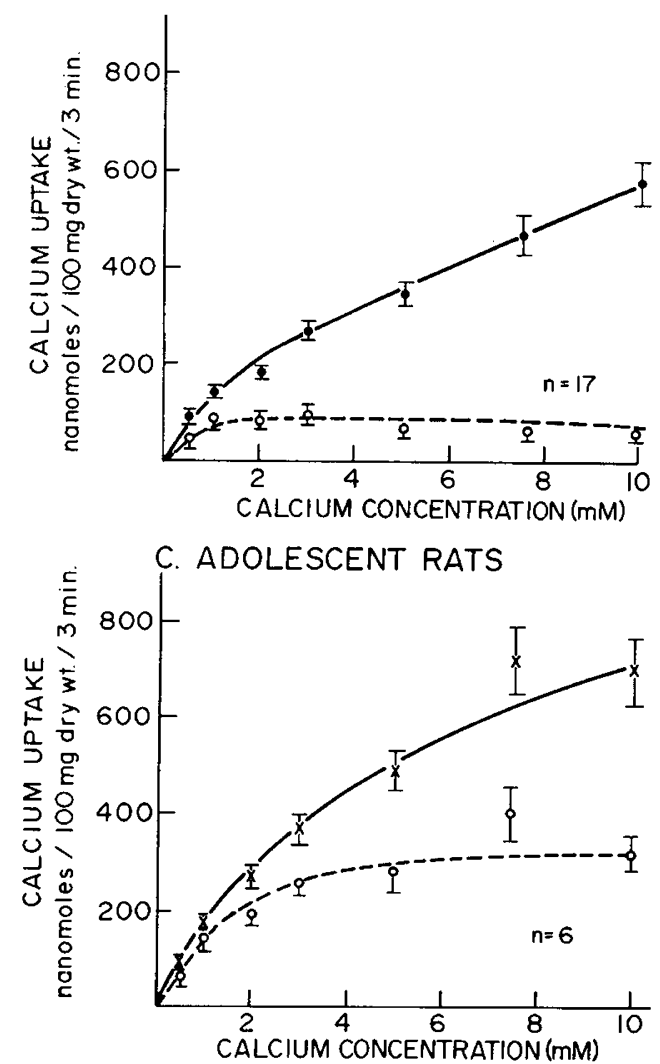

B. WEANLING RATS
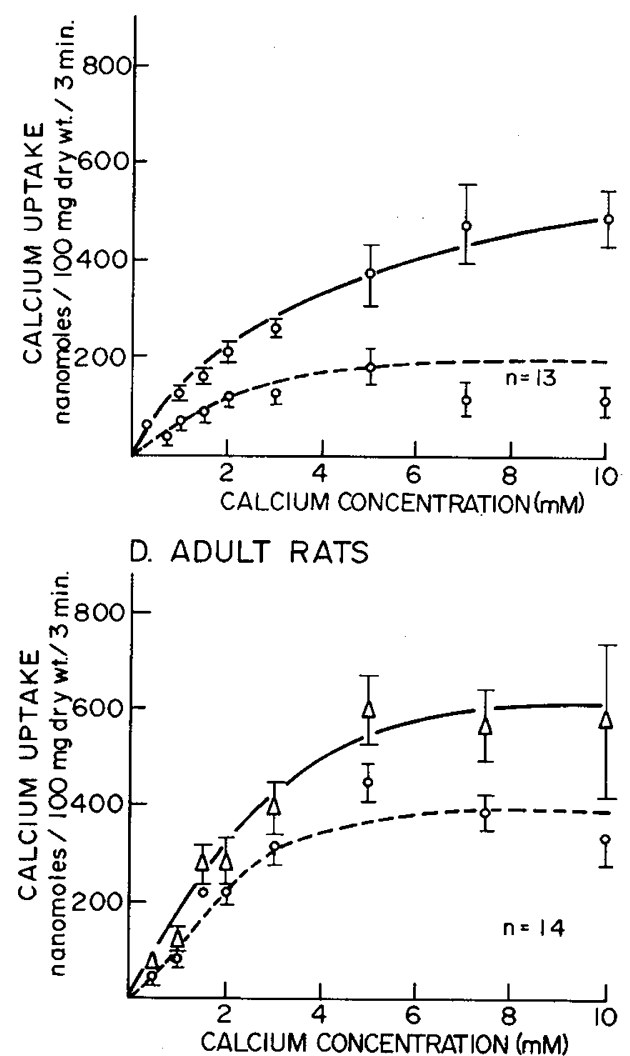

Fig. 4. Jejunal tissue uptake of calcium at $3 \mathrm{~min}$ in suckling, weanling, adolescent, and adult rats, in relation to calcium concentrations in the medium. With increasing age a more saturable process is noted. Each point represents mean \pm SD. The curves were analyzed using MichaelisMenten kinetics in the double reciprocal plot. The solid lines represent total uptake (active and passive) and the dashed lines represent the active component. $\mathrm{Km}$ and $\mathrm{Jmax}$ at each group are shown in Table 1.

DUODENUM

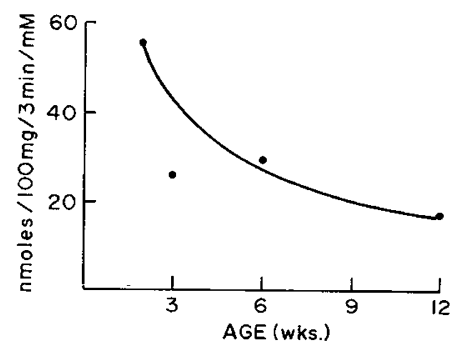

Fig. 5. The effect of age on the permeability coefficient of transmural transport of calcium (10-30 mM) in the duodenum and jejunum of the rats at different age groups. Transport of calcium at these concentrations is non-saturable. The permeability coefficient decreases with age. There is a significant difference between the slopes of the suckling and adult rats $(P<0.01)$, suggesting greater permeability of the intestinal membranes in the suckling rats compared with the adult rats.

Table 1. Apparent Km and Jmax of duodenum and jejunal calcium uptake in rats during maturation ${ }^{1}$

\begin{tabular}{|c|c|c|c|c|c|c|c|c|}
\hline & \multicolumn{2}{|c|}{ Suckling } & \multicolumn{2}{|c|}{ Weanling } & \multicolumn{2}{|c|}{ Adolescent } & \multicolumn{2}{|c|}{ Adult } \\
\hline & $\mathrm{Km}$ & Jmax & $\mathrm{Km}$ & $J \max$ & $\mathrm{Km}$ & $\mathrm{J} \max$ & $\mathrm{Km}$ & Jmax \\
\hline Duodenum & 0.58 & 79 & 0.65 & 409 & 2.0 & 465 & 1.6 & 550 \\
\hline Jejunum & 0.5 & 104 & 1.3 & 153 & 3.8 & 554 & 4.8 & 606 \\
\hline
\end{tabular}

${ }^{1} \mathrm{Km}$ values expressed in $\mathrm{mM}$ and $\mathrm{Jmax}$ values in $\mathrm{nmol} / 100 \mathrm{mg}$ dry weight $/ 3 \mathrm{~min}$.
$\mathrm{Km}$ in the suckling period to a higher $\mathrm{Km}$ as the animals mature. This pattern was seen in both duodenal and jejunal segments. Furthermore, the active component of calcium uptake appeared to increase with maturation, indicating a predominantly passive transport at the suckling period that changes to a predominately active process by the adult period. These findings are supported further by the finding of fluid/tissue ratio of $<1$ at a calcium concentration $>2 \mathrm{mM}$, indicating a predominantly passive process in the suckling period compared with a ratio of $>1$ at all other age groups, which indicates a predominantly active process (Fig. 6). It is of interest to note that this change occurs by the time of weaning. A similar observation in the change transport kinetics was noted by others for glucose transport in the rat during maturation. $\mathrm{Km}$ values for glucose transport in the small intestine of suckling rats was $7.2 \mathrm{mM}$ compared with $\mathrm{Km}$ of 16.7 $\mathrm{mM}$ in the post-weanling rat. Jmax values in suckling rats were half those observed for the post-weanling period (15). Increasing $\mathrm{Km}$ was also noted by Thomson (14) for intestinal glucose transport in rabbits. He found an apparent $\mathrm{Km}$ of $0.5 \mathrm{mM}$ at 1 wk of age and $4.0 \mathrm{mM}$ in the adult. $\mathrm{Km}$ values for 2 -wk-old and 12-wk-old rabbits were intermediate between values of the 1-wkold and the adult rabbits; thus, maturation in both rats and rabbits may be associated with a rise in $\mathrm{Km}$.

The mechanism of the changing $\mathrm{Km}$ for transport is not clear; it may be related to increased affinity for the permeant or to a lesser thickness of the unstirred water layer adjacent to the intestinal villi in the young animal as compared with the adult. But neither increased affinity nor decreased thickness of the unstirred water layer alone, without opening new sites for active transport capacity, could adequately account for the change in 


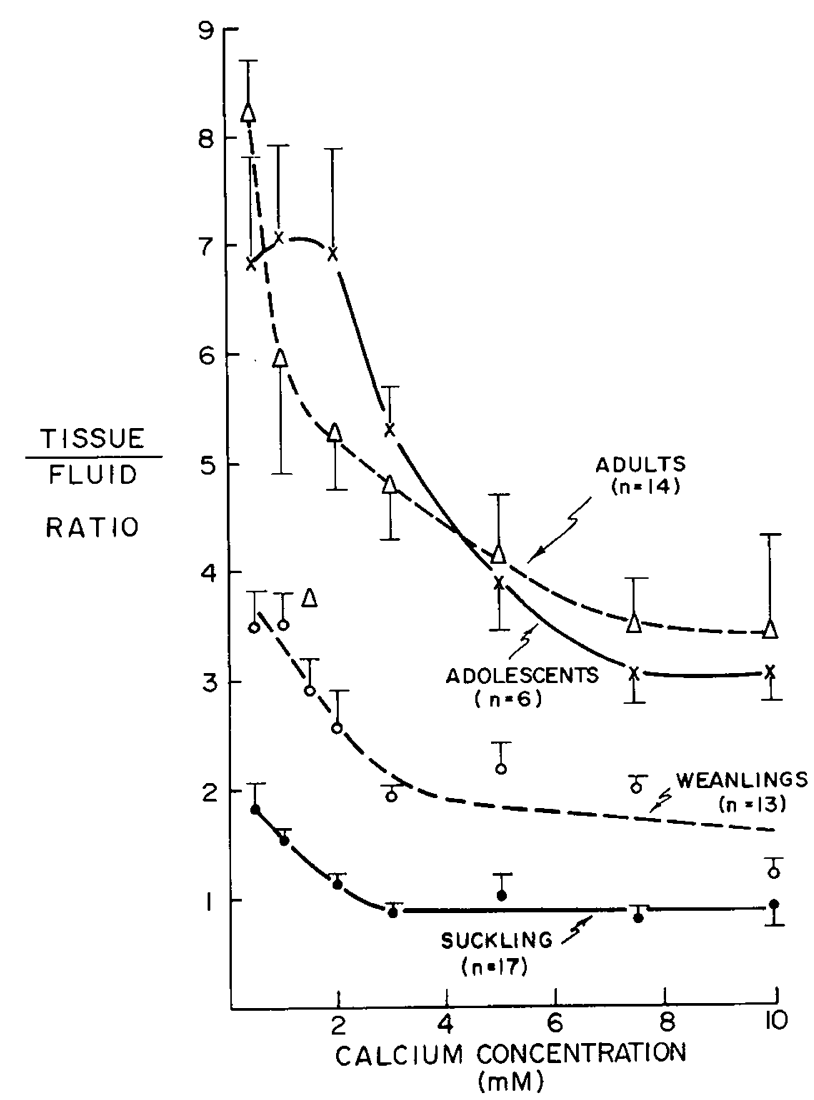

Fig. 6. The effect of age on the ratio of tissue uptake of calcium/ serosal appearance of calcium in the duodenal segments at all age groups studied. Tissue/fluid ratio was below 1 at calcium concentration above $2 \mathrm{mM}$ in suckling rats, indicating a predominately passive process. Tissue/fluid ratio was greater than 1 at all calcium concentrations in weanling, adolescent, and adult rats, indicating a predominately active process.

the maximal transport capacity. More studies are required to elucidate this maturational aspect of intestinal transport.

Concomitant with the change in $\mathrm{Km}$ there was a steady rise in the maximal transport capacity of the jejunum for calcium transport as indicated by the increase in Jmax (Table 1) with advancing maturity. In contrast, intestinal transport of calcium at higher concentrations $(10-30 \mathrm{mM})$ proceeds by a non-saturable process, suggesting a predominately passive mechanism. Furthermore, the greater rate of passive transport during the suckling period compared with the adult period suggests greater permeability of the intestine to calcium during infancy. This is supported by the gradual decrease in permeability coefficient with advancing age (Fig. 5).

These findings suggest that the intestinal transport of calcium in the rat is characterized by a maturation pattern that starts with a predominantly passive system and greater mucosal permeability during infancy and changes to a saturable system and lesser mucosal permeability during maturation. It is intriguing that the transition appears to be during the weaning period.

The factors responsible for the transition of calcium transport are not known, but some of the events which may occur during the weaning period are worth considering. First, there may be an increase in the level of serum corticosterone. In suckling rats, serum corticosterone level was reported to be $3 \mu \mathrm{g} / 100 \mathrm{ml}$. At the time of weaning a 2 -fold increase occurs and after $4 \mathrm{wk}$ of age, corticosterone levels increase to over $15 \mu \mathrm{g} / 100 \mathrm{ml} \mathrm{(2).}$
Administration of corticosterone to suckling rats resulted in a significant decrease in intestinal calcium transport, for which no effect was noted in the adult rats (16). These results imply a different mechanism for calcium transport in the rat during maturation, which may be influenced by corticosteroid level. Corticosteroid administration to suckling rats may cause early maturation of the intestinal membranes which function similar to adult rat membranes. Second, there may be an alteration in the biochemical composition of enterocyte brush-border membranes and changes in enzyme activities (3). Third, the thickness of the unstirred water layer adjacent to the intestinal villi may be less in the young than in the adult, but may increase as the animals get older. Fourth, the change to a saturable calcium transport may be related to the maturation of an intestinal calcium binding protein paralleled by the maturation of cholecalciferol hydroxylases. Indeed, immunoreactive calcium binding protein and calcium activity are markedly enhanced during the weanling period in the rat (5). Calcium transport in the intestine during early development was found not to be mediated by vitamin $D$, but a vitamin $D$-sensitive transport system developed around the time of weaning (6). This is consistent with the development of a saturable calcium transport at this transition period. Nevertheless, whatever the underlying factors may be, it is clear that the kinetic characteristics of calcium transport undergo a change as the animal matures.

\section{REFERENCES AND NOTES}

1. Batt, E. R. and Schachter, D.: Developmental pattern of some intestinal transport mechanisms in newborn rats and mice. Am. J. Physiol., 216: 1064 (1969).

2. Daniels, V. G., Hardy, R. N., Malinowska, K. W., and Nathanielsz, P. W. The influence of exogenous steroids on macromolecule uptake by the small intestine of the new born rat. Am. J. Physiol., 229: 681 (1973).

3. Forstner, G. and Garland, G.: The influence of hydrocortisone on the synthesis and turnover of microvillous membrane glycoproteins in suckling rat intestine. Can. J. Biochem., 54: 224 (1976).

4. Ghishan, F. K., Jenkins, J. T., and Younoszai, M. K.: Maturation of calcium transport in the rat small and large intestine. J. Nutr., 110:1622 (1980).

5. Gleason, W. A. and Lankford, G. L.: Intestinal calcium binding protein in the developing rat duodemum. Pediatr. Res., 16: 403 (1982).

6. Halloran, B. and Deluca, H.: Calcium transport in small intestine during early development, role of vitamin D. Am. J. Physiol., 239: 473 (1980).

7. Harrison, H. E. and Harrison, H. C.: Vitamin D and permeability of intestinal mucosa to calcium. Am. J. Physiol., 208: 370 (1965).

8. Huntsberger, D. V. and Leaverton, P. E.: Statistical inference in the Biomedical Sciences. P. 90 (Allyn and Bacon, Inc. Boston, 1970).

9. Kimberg, D. A., Schachter, D., and Schenker, H.: Active transport of calcium by the intestine: effect of dietary calcium. Am. J. Physiol., 200: 1256 (1961).

10. Ribovich, M. L. and Deluca, H. F.: The influence of dietary calcium and phosphorus on intestinal calcium transport in rats given vitamin D metabolites. Arch. Biochem. Biophys., 170: 529 (1975).

11. Sallee, V. L., Wilson, F. A., and Dietschy, J. M.: Determination of unidirectional uptake rates for lipids across the intestinal brush border. J. Lipid Res., 13: 184 (1972).

12. Schachter, D., Kowarski, S., Finkelstein, J. D., and Ma, R. W.: Tissue concentration differences during active transport of calcium by intestine. Am. J. Physiol., 221: 1131 (1966).

13. Schachter, D. and Rosen, S. N.: Active transport of ${ }^{45}$ calcium by the small intestine and its dependence on vitamin D. Am. J. Physiol., 196: 357 (1959).

14. Thomson, A. B. (with the technical assistance of Phillips, B., Chung, M., Hart, L., and Hotke, C.): Unstirred water layer and age-dependent changes in rabbitt jejunal D-glucose transport. Am. J. Physiol., 236: 685 (1979).

15. Younoszai, M. K.: Jejunal absorption of dextrose in infants and adults. J. Pediatr., 85: 446 (1974).

16. Younoszai, M. K. and Ghishan, F. K.: In vivo intestinal calcium absorption in infant rats: influence of methylprednisolone and vitamin D. Proc. Soc. Exp. Biol. Med., 158: 174 (1978).

17. Zornitizer, A. E. and Bronner, F.: In situ studies of calcium absorption in rats. Am. J. Physiol., 220: 1261 (1971).

18. Requests for reprints should be addressed to: Fayez K. Ghishan, Associate Professor, Vanderbilt University Medical Center, Department of Pediatrics, D-4100 Nashville, TN 37232.

19. Received for publication November 22, 1982.

20. Accepted for publication June 23, 1983 . 